\title{
Leveraging e-Commerce Performance through Machine Learning Algorithms
}

\author{
Adrian MICU ${ }^{\star}$, Marius GERU ${ }^{\star \star}$, Alexandru CAPATINA ${ }^{\star \star \star}$, Constantin AVRAM ${ }^{\star \star \star \star}$, \\ Robert RUSU ${ }^{\star \star \star \star \star}$, Andrei Alexandru PANAIT ${ }^{\star \star \star \star \star \star}$
}

\begin{tabular}{l} 
A R T I C L E I N F O \\
\hline Article history: \\
Accepted June 2019 \\
Available online August 2019 \\
\hline JEL Classification \\
L81, M31, C80 \\
Keywords: \\
eCommerce, digital marketing, \\
machine learning, computer vision, \\
google vision, marketing \\
intelligence
\end{tabular}

A B S T R A C T

Machine learning (ML) is quickly emerging as a new discipline and resembles to be an attractive alternative to statistical methods in various industries. An appreciation of the possible applications of ML in digital marketing and eCommerce will be proposed in this article. The authors will examine qualitative determinant factors on brand logos and correlations on companies income, with profit, the number of employees, images and number of product images on eCommerce homepage. 1420 Romanian companies were analyzed in this research in order to identify specific factors that determines the success of an eCommerce business.

(C) 2019 EAI. All rights reserved.

\section{Introduction}

Throughout time marketing research branched out and taken various forms. Different methodologies, classifications, techniques and systems were developed to serve relevant and timely information to competitive managers (Kotler, 2002). No matter the taxonomy used, as long as it provided reliable, consistent, accurate data, and actionable market intelligence, scholars appreciated and documented it. In today's digital commerce, out of the box solutions enable businesses to deploy eCommerce websites with analytics systems quickly or easily integrated with third parties. Still, when it comes to determining the identity of the brand or product, business owners face uncertainty. Considered a creative process, it is a matter of understanding the business owner or the marketing executive preferences, and how these two actors understand the targeted audience. The satisfaction level on these services is always dependent on the industry maturity and how the perceived value influences the end customers throughout the purchasing process (C. A. Adams \& Frost, 2004).

This article examines how previous authors took into attention the technical factors of eCommerce websites and available solutions for digital marketing. Based on the Nielsen model (1999), we will identify key factors in design quality impacting the overall success of a business, in order to better understand the deciding determinants in consumer behaviour and key performance indicators in eCommerce. In chapter 3 will attempt to classify brand logos, banners and screenshots of the eCommerce website based on factors like the company's founding year, number of employees and turnover. In order to achieve this, a custom model to classify images will be trained on the Google Cloud platform with AutoML Vision toolkit. The ML algorithm is trained on 1420 Romanian eCommerce websites that, by law, have to place on the homepage or terms of condition page the company name and the VAT number. With that, a Pearson correlation test is performed based on the financial information of the companies.

As Hoffman \& Novak attempted in 1996 to establish a "new medium-as-market" on the world wide web, the objective of this article is to identify new qualitative factors that might serve as deciding factors for online consumers, as the digital ad spending surpasses traditional marketing spending in the US (K. Bryan, 2019).

\section{Literature review}

Currently, businesses use eCommerce applications on both desktop computers and smartphones as digital marketing instruments, and these solutions have brought much awareness from both users and academicians regarding technological novelty. Information technologies (ITs) have radically transformed the way people buy, get information and use everyday products. Therefore, digital marketing and eCommerce are the main channels that businesses use to introduce new or existing products. Zhuofan et al. propose a 
conceptual framework in order to optimise the resource allocation and production process of an eCommerce platforms and parts website quality as follows: (1) brand awareness, (2) visitors scale, (3) user experience, (4) website speed, (5) interactive.

This research will be centred mostly on brand awareness and user experience, considering the sample we are analysing. Furthermore, we will examine the following graphical elements contained in an eCommerce website:

- brand logo

- banners and sliders

- promotional banners

- payment option/shipping methods banners

- product discount carousels

- product images

\subsection{Logos}

A company's logo acts as a critical asset in solving the challenge of indistinguishability and often decreases communication efforts for the marketing staff (Bettels \& Wiedmann, 2019). Following the point of view of Jiang, Gorn \& Galli, consumers can create mental imagery based on the logo, and reconstruct that image of the product without actually seeing the product. Thus the perceived value of the product or service is associated with the mental imagery of the brand logo. Based on this assumption, well-known brands started redesigning campaigns to simplify the brand logo(ex. Pepsi, Starbucks, Apple). This simplification follows the flat design trend that is defined by a straightforward and iconic nature (Bossel, Geyskens \& Goukens). Of course, this simplification will create more challenges to identify uniqueness and maintain brand originality in a more and more competitive market. In this sense, Kumar et al. proposed a computer vision model that classifies logos based on the text, colour or symbol for ease of identification of counterfeits. Not considering this factor can have implications beyond economic nature. Park el Al. suggested a conceptual framework based on several factors identified in the firm's logo and how it influences a company's market performance. Out of this resulted managerial, strategic insights to acknowledge logos as more efficient agents in the relationship with consumers, considering it provides aesthetic gratification. Identifying supported confirmation that there is a correlation between the value assessment of a business and the design of the brand logo is an ambitious endeavour. However, trying to classify the logos using machine learning might show that there is a qualitative difference between the turnover and how the current design of the firm's identity. Other dimensions are important as well as customer's brand commitment, functional benefit in communication, patent citations, visual gratification, revenue growth and brand familiarity as Park et Al. points out. Even so, analysing the impact of the logo in a crowdfunding campaign might be the most conclusive analysis, considering that the start-up has no previous trackable history. In this matter, Mahmooda et al. conducted research using heuristic methods into identifying if visual cues in the brand logo have an impact on backers impact in supporting a particular project.

\subsection{Ecommerce usability and user experience}

Given the substantial investment in eCommerce platforms, firms need more reliable methods concerning the examination on the usability of their software solutions before launching. Web usability studies regularly relied on questionnaire distribution as a unique approach to evaluate users' opinions of the website. Unfortunately, this method can be applied after the eCommerce solution/website is launched. There is enough proof to suggest that if users find it challenging to process product information or go through check out process, their opinion of the brand alters. Websites with inadequate design indicate an inferior brand reputation (Song \& Schwarz, 2008).

As pointed by Alonso-Virgós et al. website usability and overall graphics concerning user experience are directly affected by the web developer prior experience and training. Furthermore, it is crucial to follow the most current guidelines and implement them adequately.

Hornbæk (2006) asserted in his review that usability is not directly measured, considering the polymorphic state of qualitative work. For this reason, one must use existing models and indicators to quantify the usability of a website or a particular webpage. Out of the several proposed methods in the literature review, Fernandez et al. (2011) distinguish two main categories: empirical methods and inspection methods. If the former might appear rather usual for the latter one, the researcher has to take into consideration a range of factors like the bounce rate, average visit duration, the number of pages visited per session and conversion rate.

Nielsen (1999) proposes five quality attributes to assess the usability of user interfaces quickly and defines the terms as "methods to improve the ease-of-use during the design process." 


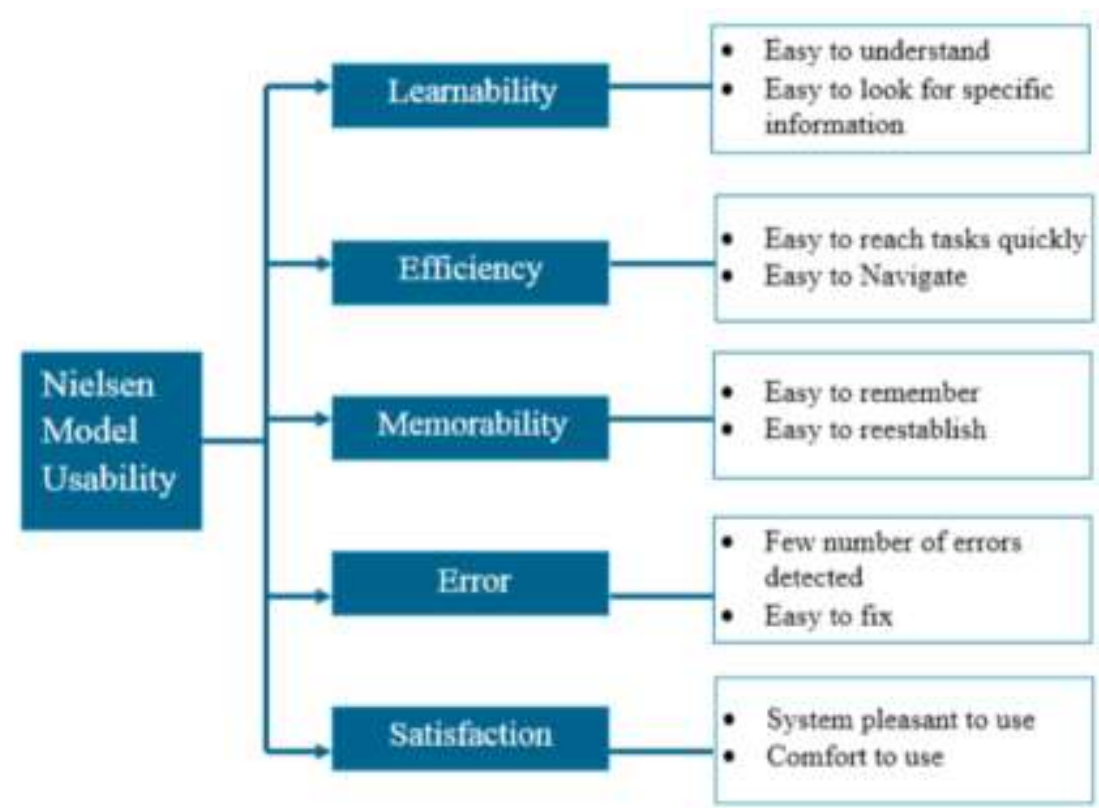

Fig. 1. Nielsen model using five usability attributes (J. Nielsen, 1999)

\subsection{Banner Ads on eCommerce websites}

A banner ad is a graphical element of advertisement displayed on an eCommerce website. Considered the most frequently used types of web advertisements by Cho, Lee, \& Tharp (2001), banners are used to present discounted offers and value-added client benefits. Usually, they contain a call to action text with a hyperlink to a specific product or landing page for more details information (Li \& Bukovac, 1999).

Even if $80 \%$ of users do not notice them (Banner Blindness) (Benway, 1998), it remains the optimal communication method to attract viewers' attention to specific products, offers or discounts. Banner blindness can happen to internet users that acquired a specific type of experience in surfing automatically, ignoring advertisements and other distractions which look similar to ad banners (Benway \& Lane, 1998). Even so, the user attention considerably drops to this type of content when he identifies specific patterns that allow him to filter the content easily, no matter if it is text, images or videos (Hsieh et al. 2012). Even if the animation slightly increases the eye fixation on the banners, the real benefit is in user recalling better this piece of content. In accordance with the point of view of Hamborg et al. (2012), animated banners tend to be more effective than non-animated ones, and the study was validated using eye-tracking technology and a set of questionnaires.

When exaggerated, or aggressive banners tend to have the opposite effect, somehow ruining the reputation or the brand or of the firm. Internet users consider pop-ups irritating and frustrating because they are interrupting the flow of actions they were pursuing. These negative emotions usually interrupt the intention of buying and tends to be associated with the identity of the brand (G. S. Bahr, R. A. Ford, 2011). Instead, polite interactions and fluid communication in banner ads can increase the rate of conversion on an eCommerce website. Even if banners started mostly on desktop computers, the market of smartphones and online media-services (TV streaming) increased as well.

\subsection{Machine learning in marketing}

We have studied popular search engines for academic articles as google scholar, science direct and research gate searching various keywords in order to identify articles in marketing journals on the machine learning topic. Even if the first articles in marketing journals included machine learning since 1998 (C. X. Ling and Chenghui Li) only in 2019, it gained momentum with more than 21 articles. The sudden rise is determined by the number of tools available for the general public and the ease of doing experiments. The first article found listed just the methodology as a potential breakthrough and how this can impact the marketing research and marketing intelligence division of companies. On the other hand, in 2019, we can see applied experiments on specific marketing issues, proposing applications and advanced decision-making system for complex business (G. Stalidis, D. Karapistolis and A Vafeiadis, 2019). The full list of articles can be seen in appendix 1. 


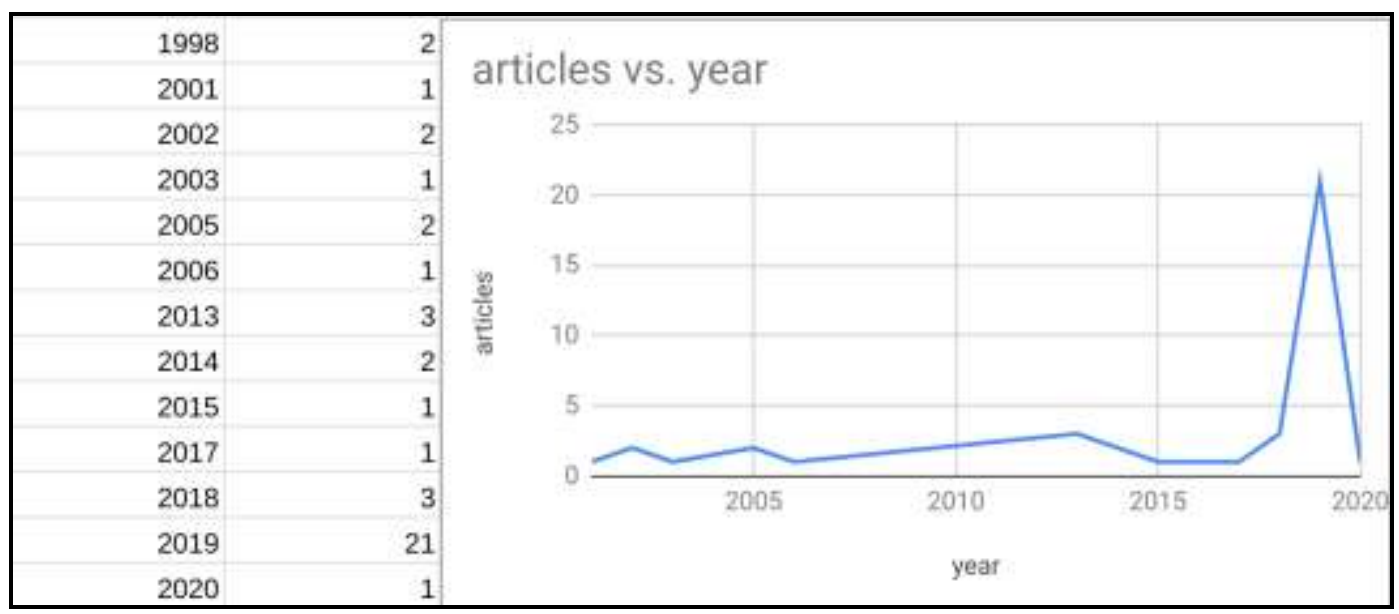

Fig. 2. Machine learning articles evolution over time

Exploiting the enormous volume of data available in the current eCommerce application and social media systems generated by, the web is becoming more accessible in order to deliver marketing intelligence. Significant efforts have been made in the development of decision assistance systems for an eCommerce platform, based on information gathered by analytics software(G. Stalidis, D. Karapistolis and A Vafeiadis, 2019). Data analytics, big data, predictive modelling and data mining, are quickly integrated with turnkey solutions, becoming powerful tools in modern marketing. Most of these solutions make use of Neural Networks as the primary tool, considering the concept is emulating the function of the human brain.

Xia Liu proposes a five-step process on how these solutions should be integrated into the usergenerated content analysis of B2B company performance:

1. Data Collection - Identification of Data Source

2. Text Preprocessing - Structured Text Data, Tokenization

3. Data Visualization - Word Cloud and LDA

4. Data Integration/Aggregation - Structured Text Data and Panel Data

5. Data Analysis - Data Analysis Results

In both data aggregation and data analysis, using machine learning methods can be used to process and transform "unstructured big data" into "small structured data" (Xia Liu, 2019).

\section{Romanian eCommerce companies Analysis}

For this analysis, it has been used a sample of 1420 companies activating in the digital commerce area. Furthermore, considering the data was collected from Romanian companies that under the law 26/1990 are required to publicly list information about the turnover number of employees, the year the company was founded and other financial information. Another critical factor in making this research possible was that under the law 441/2006, article 74, all companies that are promoting products online should have the VAT number available on the homepage and contact page. Based on this information, a database of 2372 companies was created with financial information and corresponding eCommerce website URL, from where elements of identity were collected. The difference of 952 companies out of various reasons (robots.txt, website not available or the logo could not be easily identified) was not included in this study.

Using python Jupyter lab, the logos samples were prepared for Image Classification tool in google cloud vision, in order to train a model that will be able to classify brand logo in two categories with companies established before and after 2010. For an accurate prediction, each labelled sample should have at least 100 images. All images should be categorised with a specific label (year, number of employees). Because the number of images was before 500 Google Cloud Storage was used to upload the images and all images have to be in one of the following formats: JPG, PNG, GIF, BMP, ICO. 


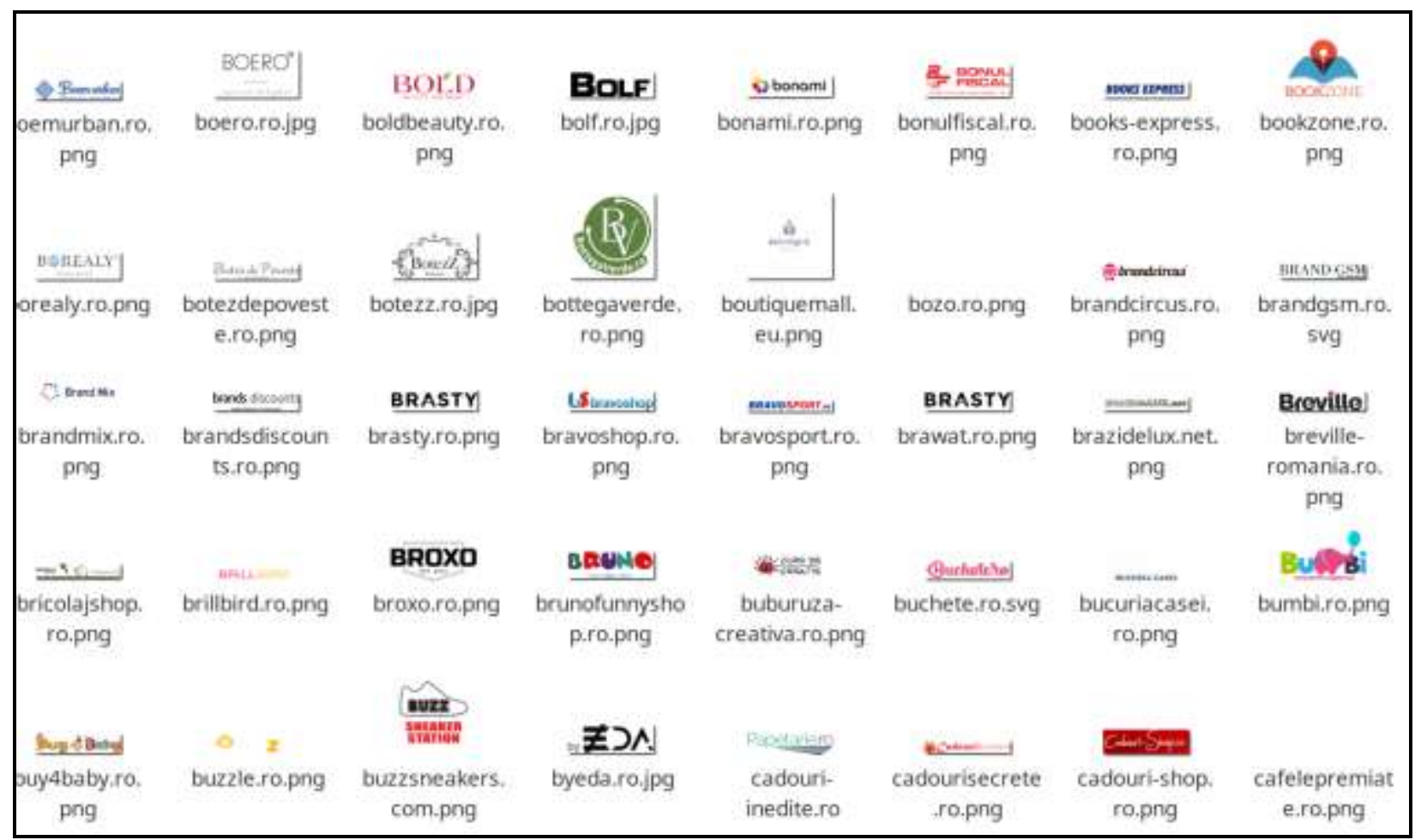

Fig. 3. Sample of the analysed logos

Also, the number of images on the homepage was mined for each eCommerce website and labelled as logo, banners or product images using a set of regular expressions as follows:

- Brand logo - logo|identity|brand|identitate

- Banners - banner|baner|promo|slider|carousel|slideshow|slide

- Products - product|produse|item

The objective of the study was to identify the strength of the association based on the Pearson correlation coefficient, taking into consideration the financial variables and number of images identified on the website's homepage. Pearson's correlation is utilised to identify a linear relationship and to test whether two variables have a positive or negative relationship, interpreting the results between the value of +1 to -1 . Naturally, the financial information of the companies indicated a very strong positive correlation; the obtained $r$ value for income and spending was 0.99 . Also, a very strong correlation was encountered between the merchandise stocks and the number of employees $(\mathrm{r}=0.84)$. Interestingly, the profits in 2018 are negatively weak correlated with the liability of the companies and very weak with the number of employees. Even if there is a moderate correlation between the number of images on the homepage and the product images, these indicators are very weakly correlated with the financial indicators. The matrix of Pearson $r$ values is listed below.

\begin{tabular}{|c|c|c|c|c|c|c|c|c|c|}
\hline & Angsjatizo18 & Datori zoveEUR & Stocuri2018EUR & Profit20iseuR & CheisuieligorueuR & Cifra2010EUA & Numarimsaini & NumuarBanere & NumarProduse \\
\hline Angalatizo18 & 1 & a. & o. $84 t i 77$ & $0.15 n g 07$ & Q. & 0845358 & acoinases & 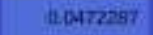 & 0,0143325 \\
\hline Datori 2018EUR & 0.842543 & 1 & 0.97224 & 0201747 & 0. & o,geans & Quarisigos: & 12.0Eabsat & a.bogisiti \\
\hline Stocuni2018EUR & oasiz? & a.9m24 & 1 & 0.124125 & agnise & 0.971469 & aoos 4 and & 6еterhas & atourse \\
\hline ProfitzoluEUR & $0.15090 \%$ & $-4.20174 y$ & te kaist & 1 & -3.1449 ad & - A vibase & 0.09314513. & -3.082774 & a.00717043 \\
\hline Cheltuiet 2018EUR & $083934 ?$ & $0.90427 ?$ & 0.9194 & -0144108 & 1 & 09998604 & $-0.005139 \mathrm{e}$ & besosea? & 0.0075241 \\
\hline Citra018EUR & 0845391 & 0.90005 & 0.971459 & $-0.11 n a 52$ & a. & 1. & -000480454 & adasorats. & -0.00750032 \\
\hline Numartmegini & 0.004 apec & 0.05155902 & 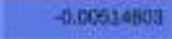 & +200314518 & $-0,00512885$ & -600496454 & 1. & 0,306966 & 0.564875 \\
\hline Numaranapere & 0.047289t & 0.0436361 & 0.05251639 & -0.007277 & 0.0503687 & ooentifos & 0.305065 & 1 & 0.150000 \\
\hline NumarProduse & +501<3328: & 0.00215178 & B 0111864 & -000717647 & -000757429 & - Dout5.3asz & 0.564875 & Q.1507า日 & 1 \\
\hline
\end{tabular}

Fig. 4. Pearson R correlation matrix, the output of python pandas

For this classification, two different datasets were created, one for the year of establishment and one for the number of employees, with 1,224 and respectively 1223 labelled images.

Each of the datasets was grouped in different subsets in order to train, validate and test the custom model that built in this process, see figure 5 . 


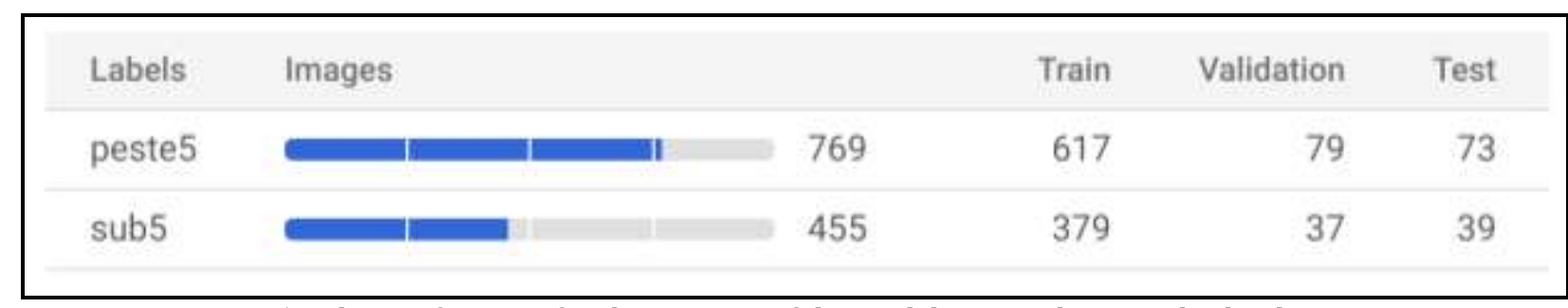

Fig. 5. Subsets of images for the training of the model. Screenshot Google cloud vision

The trained model attempts multiple parameters while searching for recognizable patterns in the uploaded training dataset. As this machine learning model identifies recognizable patterns, it uses the validation dataset to test it. The algorithms that are having the best performance are selected from the ones distinguished throughout the training step.

The last step in the Google AutoML Vision Image Classification, after the patterns have been identified, is to test for accuracy, error rate and quality and using the validation and test subset.

The training for the two datasets took more than a day (28 compute hours). The price for a compute hour is $\$ 20$, and the trained model can be used as an API or exported for edge processing in TensorFlow.

The results of the training process, is available in the Confusion Matrix and listed in the figure below, can give us specific information on how the trained model performed for each subset that was configured.

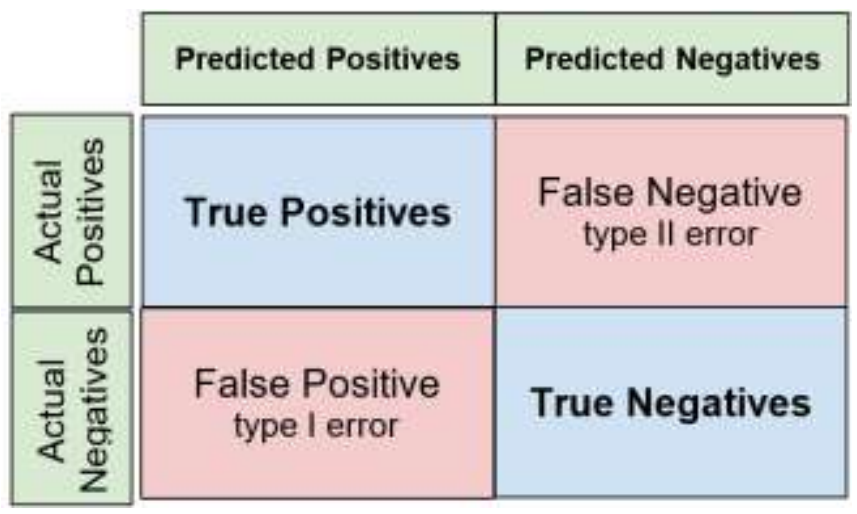

Fig. 6. Explanation of the confusion matrix based on Stehman's error matrix (1997)

To visualise the results, there are a couple of other visuals based on the Confidence threshold score that refers to the level of confidence the trained model has assigned to a category for a tested item. Depending on the level of confidence score that can be set manually on a scale from 0 to 1 , there are two other indicators that we need to take into consideration:

- Precision - shows a ratio of all the assigned tests examples that were a label to how many were supposed to be classified. In a very high precision trained model, there are fewer false positives.

- Recall - the fraction of the examples that should have had the label that is successfully retrieved out of the total assigned labels. A high recall trained model generates less false negatives.

$$
\text { Precision }=\frac{t p}{t p+f p} \quad \text { Recall }=\frac{t p}{t p+f n}
$$

For the analysis based on the number of employees, the trained model was tested on 112 images, three levels of confidence threshold were examined in order to predict companies with more than five employees based on the brand logo:

Table 1. Confidence threshold table

\begin{tabular}{|c|c|c|c|}
\hline Confidence threshold & $\begin{array}{c}\text { Precision } \\
\text { ratio }\end{array}$ & $\begin{array}{c}\text { True Positives } \\
\text { (Correctly } \\
\text { identified) }\end{array}$ & False Positives \\
\hline 0.5 & $68.32 \%$ & 59 & 32 \\
\hline 0.65 & $71.43 \%$ & 37 & 18 \\
\hline
\end{tabular}




\begin{tabular}{|c|c|c|c|}
\hline Confidence threshold & $\begin{array}{c}\text { Precision } \\
\text { ratio }\end{array}$ & $\begin{array}{c}\text { True Positives } \\
\text { (Correctly } \\
\text { identified) }\end{array}$ & False Positives \\
\hline 0.73 & $72.97 \%$ & 25 & 12 \\
\hline 0.5 & $55.17 \%$ & 44 & 39 \\
\hline 0.65 & $60.27 \%$ & 40 & 29 \\
\hline 0.73 & $66 \%$ & 33 & 21 \\
\hline
\end{tabular}

As can be seen, the trained model for the number of employees performed better than the year of establishment of companies on the tested sample. Depending on the rigorously of the analysis, different levels of confidence threshold can be selected, but also an indispensable factor needed to be taken into consideration as well: the recall value that shows us the ratio including false negatives; the correct labelling of logos for firms with less than five employees. For this analysis, the recall value was $24 \%$, and AutoML Vision recommends higher values for better results. For a similar experiment on x-ray scans on patient's chest, in order to identify pneumonia, the recall value obtained was $87.5 \%$, the sample used in this experiment was 5.824 images (Reifschneider, 2019). Considering the sample for brand logo analysis was 1.224, a more significant sample might improve the results for this test.

Confidence threshold

All labels

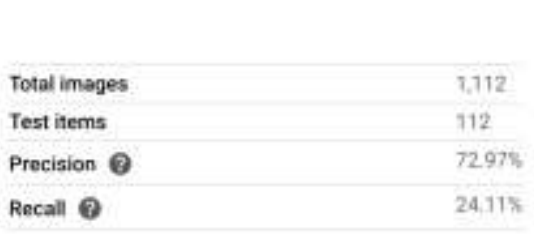

Use the slider to see which confidence threshoid works best for your model on the precision-recal tradeoff curve. mode on the precision-recsil tradeoff curve.
Leam more about these metrics and graphas.
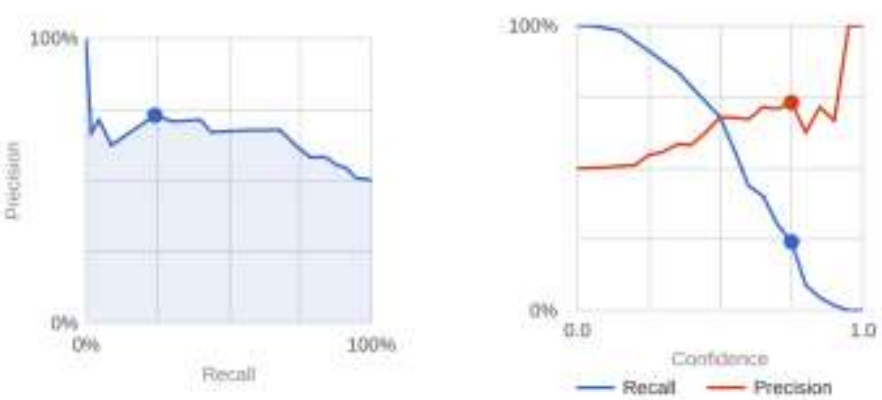

Fig. 7. Google vision trained algorithm based on number of employees output

\section{Conclusion and Managerial Implications}

Putting this together with the Miesen's usability model, we can confidently claim that we can develop Machine learning models to deal with the satisfaction and memorability dimensions. Even so, the current research only looks at particular elements in trying to assess the qualitative properties of a logo. Further models can be trained in order to check a plethora of characteristics based on quantitative metrics or qualitative data gathered from online platforms like Mechanical Turk. Based on these models, managers can better assess the quality of creative employees and test particular graphical elements before running them online. Moreover, Artificial Intelligent modules can be integrated with traffic analytics systems in order to test specific landing pages on trained models of customer behaviours on other e-commerce pages. Moreover, combining statistical tests like the Pearson $r$ test can bring considerable benefits to an eCommerce solution. Revealing consumer behaviour correlation, a dashboard with key performance indicators in real-time can be an excellent source of information for managerial decision making in a dynamic digital market. The information gathered from consumers should always be correlated with external sources like competitors financial data for better insights and an extensive overview of the market. Current eCommerce solutions come by default with tools to analyse visitors traffic and behaviour, but usually, they need integration with third-party solutions using web 2.0 standards to gain more marketing insights. To honestly approach the digital transformation challenge, one must consider better ways to understand the data generated from consumers and competition with the tools available online for the benefit of marketing intelligence.

The implementation of machine learning solutions in managing tertiary sector activities (services) it produces unprecedented implications on how organisations can lead and build new products. Qualitative evaluation of services is time-consuming and can lead to legal issues if there is a lack of specific KPI's. By 
using machine learning to align client's expectations better and to create quantifiable indicators on how the service should be delivered, it is imperative to a sustainable economy. Translating the customer's preference into instructions that a trained algorithm can evaluate promptly will increase customer satisfaction.

\section{Limitation and Future research}

Even though for a statistical test, the sample was acceptable for training a machine learning algorithm, it was moderately small. With a more significant sample, a more precise model can be developed and be trained to take into consideration different labels in evaluating the actual qualitative state of an actual logo. A comparative analysis of samples from different countries, industries or fortune 500 company can show characteristics in design patterns. Furthermore, the analysis can be extended to other types of graphical materials like promotional banners, flyers and screenshot of the entire website. Dividing the banners into subcategories like promotions, payment options, shipping details, type of support offered and home page slider can bring significant insights on how to better optimise digital marketing campaigns.

\section{Acknowledgement}

This work was supported by a grant of the Romanian Ministry of Research and Innovation, CCCDI - UEFISCDI, project number PN-III-P1-1.2-PCCDI-2017-0800 / 86PCCDI/2018 - FutureWeb, within PNCDI III.

\section{References}

1. J. Bettels, K. P.r Wiedmann, Brand logo symmetry and product design: The spillover effects on consumer inferences, Journal of Business Research Volume 97, April 2019, Pages 1-9

2. Adams, C. A., \& Frost, G. R. (2004). The Development of Corporate Web-sites and Implications for Ethical, Social and Environmental Reporting through These Media. Edinburgh: The Institute of Chartered Accountants of Scotland.

3. Jiang, Y., Gorn, G. J., Galli, M., \& Chattopadhyay, A. (2015). Does your company have the right logo? How and why circular-and angularlogo shapes influence brand attribute judgments. Journal of Consumer Research, 42(5), 709-726.

4. V. Bossel, K. Geyskens, C. Goukens, Facing a Trend of Brand Logo Simplicity: The Impact of Brand Logo Design on Consumption, Food Quality and Preference, 2018

5. Whan Park, Andreas B. Eisingerich, Gratiana Pol, Jason Whan Park, The role of brand logos in firm performance, Journal of Business Research 66 (2013) 180-187

6. Mahmooda, J. Luffarellib, M. Mukeshc, What's in a logo? The impact of complex visual cues in equity crowdfunding, Journal of Business Venturing 34 (2019) 41-62

7. Benway, J. P. (1998). Banner blindness: The irony of attention grabbing on the world wide web. Houston, Texas: Rice University Research.

8. Benway, J. P., \& Lane, D. M. (1998). Banner blindness: Web searchers often miss “Obvious” links. Rice University, Internet Technical Group.

9. Y. C. Hsieh, K. H. Chen, M. Y. Ma, Retain viewer's attention on banner ad by manipulating information type of the content, Computers in Human Behavior 28 (2012) 1692-1699

10. Cho, C., Lee, J., \& Tharp, M. (2001). Different forced-exposure to banner advertisements. Journal of Advertising Research, 41, 45-56.

11. Li, H., \& Bukovac, J. L. (1999). Cognitive impact of banner ad characteristics: An experimental study. Journalism and Mass Communication Quarterly, 76(2), 341-353.

12. K.-C. Hamborg, M. Bruns, F. Ollermann, K. Kaspar, The effect of banner animation on fixation behavior and recall performance in search tasks, Computers in Human Behavior 28 (2012) 576-582

13. G. Susanne Bahr, Richard A. Ford, How and why pop-ups don't work: Pop-up prompted eye movements, user affect and decision making, Computers in Human Behavior 27 (2011) 776-783

14. Song H, Schwarz N. If it's hard to read, it's hard to do: processing fluency affects effort prediction and motivation. Psychological Science 2008;19(10):986-8.

15. Lucía Alonso-Virgósa, Jordán Pascual Espadab, Rubén González Crespo, Analysing compliance and application of usability guidelines on efficient and understandable controls, Computer Standards \& Interfaces, 66 (2019)

16. Hornbæk, K., 2006. Current practice in measuring usability: challenges to usability studies and research. Int. J. Hum. Comput. Stud. 64 (2), 79-102.

17. Fernandez, A., Insfran, E., Abrahão, S., 2011. Usability evaluation methods for the web: a systematic mapping study. Inf. Softw. Technol. $53(8), 789-817$.

18. Stehman, S. V. (1997). Selecting and interpreting measures of thematic classification accuracy. Remote Sensing of Environment, 62(1), 77-89. doi:10.1016/s0034-4257(97)00083-7

19. Jakob Nielsen, Designing Web Usability: The Practice of Simplicity, New Riders Publishing Thousand Oaks, CA, USA,1999

20. Hoffman, D. L., \& Novak, T. P. (1996). Marketing in Hypermedia Computer-Mediated Environments: Conceptual Foundations. Journal of Marketing, 60(3), 50. doi:10.2307/1251841

21. Kotler, P. (2002). Marketing management: Analysis, planning, implementation and control, (11th ed.). Englewood Cliffs, New Jersey: Prentice Hall.

22. J. Reifschneider, 19, july 2019, https://towardsdatascience.com/google-cloud-automl-vision- for-medical-image-classification$\underline{76 d f b f 12 a 77 e}$

23. G. Stalidis, D. Karapistolis, A. Vafeiadis (2015), Procedia-Social and Behavioral Sciences Marketing Decision Support Using Artificial Intelligence and Knowledge Modeling: Application to Tourist Destination Management

24. X. Ling, Chenghui Li (1998), KDD-98, Data Mining for Direct Marketing: Problems and Solutions

25. Xia Liu (2019), Industrial Marketing Management, Target and position article - Analyzing the impact of user-generated content on B2B Firms' stock performance: Big data analysis with machine learning methods

26. K. Bryan (2019), https://insights.digitalmediasolutions.com/articles/digital-media-surpasses -traditional-media 
2006, Geng Cui, Man Leung Wong, Hon-Kwong Lui, Management Science, Machine Learning for Direct Marketing Response Models: Bayesian Networks with Evolutionary Programming 1998, Charles X. Ling and Chenghui Li, KDD-98, Data Mining for Direct Marketing: Problems and Solutions 2014, Pål SundsøyJohannes BjellandAsif M. IqbalAlex "Sandy" PentlandYves-Alexandre de Montjoye, Social Computing, Behavioral-Cultural Modeling and Prediction, Big Data-Driven Marketing: How Machine Learning Outperforms Marketers' Gut-Feeling

2003, Kwok-Wai Cheung James T. Kwok Martin H. Law Kwok-Ching Tsuia, Decision Support Systems, Mining customer product ratings for personalized marketing

2017, Keng L. Siau, Yin Yang, MWAIS 2017 Proceedings, Impact of Artificial Intelligence, Robotics, and Machine Learning on Sales and Marketing

2005, Natalie Glance Matthew Hurst Kamal Nigam Matthew Siegler Robert Stockton Takashi Tomokiyo, KDD '05, Deriving marketing intelligence from online discussion

2002, Chaochang Chiu, Expert Systems with Applications, A case-based customer classification approach for direct marketing

2001, Indranil Bose, Radha K. Mahapatra, Information \& Management, Business data mining - a machine learning perspective

2013, Meena Rambocas, João Gama, FEP Working Papers, Marketing Research: The Role Of Sentiment Analysis

2014, Jidong Huang, Rachel Kornfield, Glen Szczypka, Sherry L Emery, Tobacco Control, A cross-sectional examination of marketing of electronic cigarettes on Twitter

2002, K.P. Bennett ; S. Wu ; L. Auslender, IEEE, On support vector decision trees for database marketing

1998, Dirk Van den Poel, Rough Sets in Knowledge Discovery 2. Studies in Fuzziness and Soft Computing, Rough Sets for Database Marketing

2013, K. Wisaeng, International Journal of Soft Computing and Engineering, A Comparison of Different Classification Techniques for Bank Direct Marketing

2005, Natalie Glance Matthew Hurst Kamal Nigam Matthew Siegler Robert Stockton Takashi Tomokiyo, WWW '05 Special interest tracks and posters of the 14th international conference on World Wide Web, Analyzing online discussion for marketing intelligence

2019, Daniel D. Prior, Joona Keränen, Australasian Marketing Journal (AMJ), Revisiting contemporary issues in B2B marketing: It's not just about artificial intelligence

2019, Yogesh K.Dwivedi, International Journal of Information Management, Artificial Intelligence (AI): Multidisciplinary perspectives on emerging challenges, opportunities, and agenda for research, practice and policy

2019, Zaheer Allam Zaynah A. Dhunny, Cities, On big data, artificial intelligence and smart cities

2019, Piotr Ładyżyński, Kamil Żbikowski, Piotr Gawrysiak, Expert Systems with Applications, Direct marketing campaigns in retail banking with the use of deep learning and random forests

2019, Susan A. M. Vermeer, Theo Araujo, Stefan F. Bernritter, Gudavan Noort, International Journal of Research in Marketing, Seeing the wood for the trees: How machine learning can help firms in identifying relevant electronic word-of-mouth in social media

2019, Xia Liu, Industrial Marketing Management, Target and position article - Analyzing the impact of usergenerated content on B2B Firms' stock performance: Big data analysis with machine learning methods

2018, Andrés Martínez, European Journal of Operational Research, A machine learning framework for customer purchase prediction in the non-contractual setting

2019, Christofer Laurell et. al, Journal of Business Research, Exploring barriers to adoption of Virtual Reality through Social Media Analytics and Machine Learning - An assessment of technology, network, price and trialability

2018, Xu Wang et. al, Omega, On the optimal marketing aggressiveness level of C2C sellers in social media: Evidence from china

2019, George Baryannis et. al, Future Generation Computer Systems, Predicting supply chain risks using machine learning: The trade-off between performance and interpretability

2019, Hamed Ghoddusi et. al, Energy Economics, Machine learning in energy economics and finance: A review 2018, Niladri Syam, Arun Sharma, Industrial Marketing Management, Waiting for a sales renaissance in the fourth industrial revolution: Machine learning and artificial intelligence in sales research and practice

2013, Francisco J. Martínez-López, Jorge Casillas, Industrial Marketing Management, Artificial intelligencebased systems applied in industrial marketing: An historical overview, current and future insights

2015, George Stalidis, Dimitrios Karapistolis, Athanasios Vafeiadis, Procedia - Social and Behavioral Sciences, Marketing Decision Support Using Artificial Intelligence and Knowledge Modeling: Application to Tourist Destination Management

2019, Roland T. Rust, International Journal of Research in Marketing, The future of marketing 
2019, Angelo Di Gregorio et. all, Journal of Retailing and Consumer Services, Employability skills for future marketing professionals

2019, Gerardo Zarazua de Rubens, Energy, Who will buy electric vehicles after early adopters? Using machine learning to identify the electric vehicle mainstream market

2019, Ting-Hsuan Chen, Applied Soft Computing, Do you know your customer? Bank risk assessment based on machine learning

2020, Satu Elisa Schaeffer, Sara Veronica Rodriguez Sanchez, , Forecasting client retention A machinelearning approach

2019, Omer Faruk Beyca, Energy Economics, Using machine learning tools for forecasting natural gas consumption in the province of Istanbul

2019, Huey Yii “Daphane” Tan, Australasian Marketing Journal (AMJ), The reciprocal effects of loneliness and consumer ethnocentrism in online behavior

2019, Hailong Cui, European Journal of Operational Research, Predicting product return volume using machine learning methods

2019, Edmir Kuazaqui, Teresinha Covas Lisboa, , Marketing: The Evolution of Digital Marketing

2019, O. Yu. Patlasov, O. A. Mamaev, V. V. Shepelev, T. B. Smirnova, , MARKETING RESEARCH OF THE MODIFIED STARCH MARKET

2019, Christophre Georges, Javier Pereira, SSRN Electronic Journal, Market Stability with Machine Learning Agents

2019, Marketing analytics in the age of machine learning

2019, Orogun Adebola, Bukola Onyekwelu, , Predicting Consumer Behaviour in Digital Market: A Machine Learning Approach 